\title{
Stylistic Analysis of The Great Gatsby from Lexical and Grammatical Category
}

\author{
Xiangqi Liu \\ Qingdao University of Science and Technology, Qingdao, China \\ Email: shirley780204@yahoo.com.cn
}

\begin{abstract}
The thesis tries to adopt the method used by Leech and Short in their book Style in Fiction to make a relatively overall and objective analysis of the novel's language from lexical and grammatical Category. As far as the lexical features are concerned, the author employs special lexical items and lexical clusters. The lexical deviation and word connotations are mainly used for characterization and theme revelation. In terms of the syntactical aspects, narrative sentence type and the contrast of registers are employed, and the author's sentence endings with elaborate appositions and prepositional phrases provide an effective way to describe the surroundings and evoke moods, serving to generate suspense as well as to create interest and expectation on the part of the reader.
\end{abstract}

Index Terms-lexical category, adjective, lexical cluster, grammatical category, sentence structure, appositional phrase, prepositional phrase

Stylistic analysis is an attempt to find the artistic principles underlying a writer's choice of language. However, as all texts have their individual qualities, the linguistic features which recommend themselves to the attention in one text will not necessarily be important in another text by the same or a different author. Therefore, Leech and Short (2000: 74-82) propose a useful checklist of linguistic and stylistic categories which are placed under four general headings: lexical categories, grammatical categories, figures of speech, and cohesion and context, each containing several subcategories, and inevitably with some overlapping. Lexical categories are used to find out how choice of words involves various types of meaning. They may contain a general description of vocabulary choice, and examinations of nouns, adjectives, verbs, adverbs, etc. Grammatical categories, on the other hand, probe into such branches as sentence types, sentence complexity, clause types, clause structure, noun or verb phrases, word classes, and so on and so forth. This chapter is devoted to a general analysis of the stylistic features in Fitzgerald's The Great Gatsby from the lexical and grammatical category.

\section{LEXICAL CATEGORY}

\section{A. Adjectives}

One of the simplest yet most profound reasons The Great Gatsby is considered as an American classic is its use of language. Fitzgerald's language is figurative, which is full of images -- concrete verbal pictures appealing to the senses, by the employment of adjectives. Fitzgerald frequently uses adjectives to create romantic sensation and visualize the scene and hence heightens the theme.

Her face was sad and lovely with bright things in it, bright eyes and a bright passionate mouth -- but there was an excitement in her voice that men who had cared for her found difficult to forget: a singing compulsion, a whispered "Listen", a promise that she had done gay, exciting things just a while since and that there were gay, exciting things hovering in the next hour. (p. 13)

This sentence is densely sparked with adjectives. It is interesting that Fitzgerald often links adjectives that seem contradictory, e.g. sad and lovely. But this technique visualizes the character Daisy, and the repetition of the next adjective "bright" seems to imply that Daisy is bright. However, the word "sad" denies this by its meaning; thus the description gives us a suspicious impression. With Fitzgerald's employment of adjectives and participles used as attributives, Daisy's voice is sensate and hence, paves the way for Gatsby's comment: "Her voice is full of money."

The extensive use of adjectives in sentences like the above ones helps to convey the author's interpretation of the scene and is typical of Fitzgerald's use of subjective description. Here is another example:

But his heart was in a constant, turbulent riot. The most grotesque and fantastic conceits haunted him in his bed at night. A universe of ineffable gaudiness spun itself out in his brain while the clock ticked on the wash-stand and the moon soaked wet light his tangled clothes upon the floor. Each night he added to the pattern of his fancies until drowsiness closed down upon some vivid scene with an oblivious embrace. (p. 132)

There are altogether nine adjectives (constant, turbulent, grotesque, fantastic, ineffable, tangled, each, vivid, and oblivious) in the passage, more than $10 \%$ of the total number. These adjectives are all attributives and have nothing to do with physical attributes. The "constant, turbulent riot" is the background of his dream and the adjectives "grotesque, fantastic" modifying "conceits" drop a hint that the dream is inaccessible. A description such as "the moon soaked with wet light his tangled clothes" helps the reader to visualize the scene in the manner Fitzgerald intends. The adjective 
"vivid" make the scene more real but the adjective "oblivious" works in an opposite way. These adjectives combine together to form a dreamy world where reality and illusion begin to blur. "In the process of combining lyrical description with objective circumstance he mastered the connections between themes and narration." (Prigozy, 2001: 95)

The automobile, serving a function of showing wealth, has a very special meaning in The Great Gatsby. "Like all of Gatsby's possessions, it is far more than a material object; it is a sign of the pathetic mystique which serves Gatsby -the representative of the American dream -- as he worships a kind of ultimate value that far transcends any material object at all." (Cooperman, 1996: 34) Gatsby's "gorgeous car" is described in details:

It was a rich cream color, bright with nickel, swollen here and there in its monstrous length with triumphant hat-boxes and supper-boxes and tool-boxes, and terraced with a labyrinth of wind-shields that mirrored a dozen suns. Sitting down behind many layers of glass in a sort of green leather conservatory we started to town. (p. 85)

Fitzgerald relies on the style to evoke a car appropriate for Gatsby. "The car itself is described with an interesting series of adjectives -- adjectives which communicate a sense not only of opulence, but of combined brittleness and softness, almost of decay." (Cooperman, 1996: 35) With the characteristic use of the surprising adjective in "triumphant hat-boxes", Fitzgerald actually implies that Gatsby takes pride in his automobile, as he does in all his possessions; he is "triumphant" financially and socially. However, the fact that this car kills Myrtle later on shadows its triumph and causes the death of Gatsby indirectly. Besides, Fitzgerald uses carefully selected details of description to convey through each automobile the character and vision of its owner.

Besides his extensive use of adjectives, another prominent characteristic of Fitzgerald's use of adjectives lies in his linkage of apparently incompatible nouns and adjectives to produce startling but thematically evocative effects and his pattern of linking adjectives that seem contradictory. For example, the "triumphant hat-boxes" of Gatsby's car and the "blue gardens" of his parties, both suggest the magnificent but unreality of his vision of self.

As theme is most dramatically expressed through character, Fitzgerald uses the people he created to convey his message to the reader. We can easily see how Fitzgerald uses such technique to depict the characters in the novel. When Nick arrives at the Buchanans for dinner, the three characters are described for the first time in terms that emphasize their physical presence. Here are Nick's descriptions:

It was a body capable of enormous leverage -- a cruel body. (p. 10)

It is interesting that the "body" is described as "cruel" here, for normally "cruel" is referred to a person and not to a body. Fitzgerald doesn't describe that Tom is cruel but that his body is cruel, suggesting a separation between his body and himself, as if Tom's cruel character may assert itself apart from his will.

The other girl, Daisy ... she laughed, an absurd, charming little laugh, and I laughed too and came forward into the room. (p. 12)

The adjective "absurd" with the meaning of "ridiculously incongruous or unreasonable" combines queerly with the adjective "charming" with the meaning "attracting". "Absurd" seems to imply that Daisy's life is aimless emptiness, it is even absurd when her laugh is charming. And the words "an absurd, charming little laugh" suits her habit, which we will come to know, of gushing overstatement: "I'm paralyzed with happiness." More or less, Nick hints that Daisy's manner may be crafty. 15)

Her grey sun-strained eyes back at me with polite reciprocal curiosity out of a wan, charming discontented face. (p.

"Charming discontented" is also an example of the surprising pattern of linking adjectives that seems contradictory. As we can see, when one is restlessly unhappy or discontented, how can his/her face be charming? But this is the case, as Miss Jordan Baker is seen in this story as a person, who dealt in universal skepticism and is very uncertain about her own thoughts, movements, and feelings.

Fitzgerald produces more elaborate writing with his use of adjectives, and the adjectives he used help present the illusionary aspect of Gatsby's world. In a sense, Fitzgerald is very imaginative.

\section{B. Lexical Clusters and Depiction of Three Main Characters}

At the very beginning of the novel, the narrator recalls the impression Gatsby makes on him, which sets the tone of the story:

Only Gatsby, the man who gives his name to this book, was exempt from my reaction -- Gatsby, who represented every thing for which I have an unaffected scorn. If personality is an unbroken series of successful gestures, then there was something gorgeous about him, some heightened sensitivity to the promises of life, as if he were related to one of those intricate machines that register earthquakes ten thousand miles away. This responsiveness had nothing to do with that flabby impressionability which is dignified under the name of the 'creative temperament' -- it was an extraordinary gift for hope, a romantic readiness such as I have never found in any other person and which it is not likely I shall ever find again. (p. 8)

Lexically speaking, there are not a few abstract nouns commenting on Gatsby in this passage, many of which are modified by multi-syllabic adjectives, such as "something gorgeous, heightened sensitivity, promises, responsiveness, impressionability, temperament, extraordinary gift for hope, romantic readiness". This lexical cluster, indicating personal quality and temperament rather than outward appearance of Gatsby, leads our attention to the speech and thought of the character, and his dreamy inner world, rather than on the local realistic world of the novel. The 
recurrence of a number of abstract nouns reveals Gatsby's idealistic aspect of personality, and sets up an illusive world, which he is eager to hold but in which there is nothing substantial. This seems to indicate that Gatsby's ideal is unattainable and his American Dream is doomed to corruption. Thus from the opening of the story, the narrator sets Gatsby's idealistic and tragic image.

Characterization in The Great Gatsby is not a straightforward business since it is frequently developed through nuance, through employment of suggestive words rather than revealed through objective description. See the following rare example that is used to describe Gatsby directly:

He smiled understandingly--much more than understandingly. It was one of those rare smiles with a quality of eternal reassurance in it, that you may come across four or five times in life. It face--or seemed to face--the whole eternal world for an instant, and then concentrated on you with an irresistible prejudice in your favor. (p. 49)

It is supposed to be a description of Gatsby's outward smile, but abstract words like "eternal reassurance, eternal world, and irresistible prejudice" are still related to Gatsby's personal temperament. "Eternal reassurance and irresistible prejudice" together with "concentrated" justify Gatsby's understanding smile that is to be taken seriously and apparently reflect the purposefulness in Gatsby's personality. Besides purposefulness and romantic idealism, Gatsby is also a personification of features like wealth, ostentation, selfishness, materialism and criminality, some of which overlap with those of other characters in the novel. (Cooperman, 1996: 60) But it is the polarization from others marked by words indicating romantic idealism that sets Gatsby apart from the other major characters in the novel and constitutes the constantly reiterated foundation of the narrator's approval of him. Thus the author's moral attitude is revealed through his use of lexical clusters.

In contrast to Gatsby's romantic idealism is the leisure class's emptiness, a case in point is the portrayal of Tom Buchanan, one of the major characters in the novel, who together with Daisy, his wife, is the prime representative of the upper society, symbolizing the corruption of the American Dream. And this is apparent in the lexical items used to characterize him.

Words that depict Tom include: restlessness, physical strength, virility, athleticism, dandyism, wealth, materialism, extravagance, vulgarity, possessiveness, jealously, untrustworthiness, selfishness, carelessness, cruelty, physical violence, aggression, arrogance, cynicism, contemptuousness, insolence, prejudice, shallowness. Many of these features are explicitly stated, or implied, in the two pages very early in the novel which introduce Tom into the story. For example, when Nick the narrator introduces the Buchanans, he first uses such words to introduce the reader to the kind of hedonistic lifestyle they lead: "drifted here and there unrestfully", (p. 11) "I felt that Tom would drift on forever seeking, a little wistfully, for the dramatic turbulence of some irrecoverable football game.” (p. 12)

Their lives without purposes and the idea of the Buchanans' mental or moral as well as physical rootlessness are conveyed through the use of lexical items with the semantic meaning of restlessness.

The narrator's direct description of Tom is also focused on his unrestfulness. We all remember Fitzgerald's physical description of Buchanan -- "a great pack of muscle shifting when his shoulder moved under his thin coat" (p. 12). As the narrator arrives at his home, Tom talks to him on his porch, "his eyes flashing about restlessly" (p. 13). Later they go into the living room, where he is described as "hovering restlessly about the room" (p. 15). Incidents and phrases amplify and dramatize these semantic features as the novel progresses, picking up and highlighting what Nick sees as the crucial ones as he moves towards a judgment on Tom.

Some of the constituent features which define Tom occur in some other lexical clusters, so Tom overlaps with Daisy in other respects (handsomeness, selfishness, restlessness). They are all classified as purposeless, hopeless, and spiritually dead. Lexical items with overlapping semantic features appear so frequently that they become a clue to a fuller understanding of all that happens: they suggest the discontent and unfulfillment, the waste and frustration of energies, the lack of ideals, beliefs and goals which plagues everyone in the book.

Thus, lexical clusters with different semantic features, as a technique for the analysis of the character, serve as the basis for the categorization of characters.

\section{GRAMMATICAL CATEGORY}

\section{A. Narrative Sentence Type}

In English, degrees of formality are indicated by linguistic features at phonological, lexical and grammatical/syntactic levels. Fitzgerald's syntactic formality is greatly demonstrated through his relatively long narrative sentence type. As a consequence, readers are likely to feel that Fitzgerald's style of writing is rather more demanding and appears more formal. This formal and serious register, the complexity of which is vivid in describing inner feelings and emotional changes, helps to highlight the narrator's complex feelings towards his era: his lament over the corruption of the American Dream and the moral decadence, and his admiration for Gatsby's romanticism and idealism. (Cooperman, 1996: 96)

In spite of the comparatively high sentence-length average, sentences in The Great Gatsby are not particular complex in the sense that we do not find many examples of clauses embedded inside other clauses. There is some subordination, but it would appear that most of the complexity in the extract occurs at phrasal level, and the dominant pattern of clauses in this extract would appear to be a series of main clauses coordinated together. For more detailed analysis of this syntactic texture, look at the following example: 
The groups change more swiftly, swell with new arrivals, dissolve and form in the same breath; already there are wanderers, confident girls who weave here and there among the stouter and more stable, become for a sharp, joyous moment the center of a group, and then, excited with triumph, glide on through the sea-change of faces and voices and color under the constantly changing light. (p. 42)

This is the longest sentence (74 words) in the description about Gatsby's oncoming party, thus comparatively complex. However even the longest sentence carries no loss of clarity: its first clause is composed of four coordinated verbs, and coordinated with it is a "there" construction accompanied by an apposition. The apposition "confident girls" is embedded with a defining clause, in which "weave", "become", and "glide", three verbs coordinate together. The syntactic analysis of the long sentence apparently shows the author's preference for coordination over subordination. As a consequence, the passage is reasonably easy to read, because it takes less mental effort for readers to unscramble clauses in coordination.

Different sentence structures take on different thematic values and literary significance. In the sentence examined above, the coordination of verbs in alliance with their simple, or non-progressive aspect, helps to make the description appear to move quickly from one group to the next rather than dwell on particular moments for a long time, hence highlighting the atmosphere of chaos and mindlessness.

\section{B. Use of Appositional Phrases}

On the level of plot, the sophisticated narrator seems to criticize the American Dream, its illusions and excesses -- he refers scornfully to Gatsby's "appalling sentimentality" (p. 107) and to the "foul dust" that "floated in the wake of his dreams" (p. 8). But syntactically, in some of the most beautifully written and memorable lines of the novel, Nick demonstrates not scorn but, rather, ready sympathy for Gatsby and for those ideological presuppositions that underlie Gatsby's ambitions. Nick tells Gatsby's story in a lyrical style. This lyricism is accomplished grammatically in the continuation of sentences seemingly reluctant to end. A representative of this syntactic feature is the appositional phrase, in which his sympathy for Gatsby's ideological presupposition as well as his condemnation to aimless pursuit and capitalist aspiration is clearly seen.

In Nick's narrative, the first part of the sentences, sometimes just an independent clause, does the work of plot development, moving the narrative forward in time and place and event, but the second part -- some drawn-out endings, often syntactically unnecessary -- can go on to evoke accumulations of romantic sensitivity -- feelings or indefinite excitements. These sentence endings frequently constructed with elaborate appositions cultivate heightened sensation, and reveal the romantic conceits and aspirations of these ambitious people.

Consider Nick's account of Gatsby's entry into his dream world:

For a while these reveries provided an outlet for his imagination; they were a satisfactory hint of the unreality of reality, a promise that the rock of the world was founded securely on a fairy's wing. (pp. 95-96)

This sentence begins with a time-adverbial, establishing duration and "reveries" as what is being talked about. Then through a second-start "they", it elaborates itself into apposition, which is syntactically unnecessary and surplus, but seemingly caused by sensitivity to words like "imagination" and "reverie". In the lush ending of the sentence occurs the "fairy's wing" that is connected directly to the embodiment of Gatsby's dreaming, Daisy Buchanan, whose maiden name is Fay. Nick hereby conveys a magical destiny to Gatsby's adventure.

Another example occurs when Nick describes Gatsby's romantic excitement as a young army officer when he first views Daisy's house:

There was a ripe mystery about it, a hint of bedrooms more beautiful and cool than other bedrooms, of gay and radiant activities taking place through its corridors, and of romances that were not musty and laid away already in lavender, but fresh and breathing and redolent of this year's shining motor-cars and of dances whose flowers were scarcely withered. (p. 141)

These sentence endings sketch over "beautiful bedrooms, radiant activities, romances laid away in lavender, shinning motor-cars and flowers scarcely withered", all of which make up a world of wealth and possessions. Everything contained in this appositive is suggestive, displaying the mystery as well as wealth that surround Daisy, thus depicting her as a golden girl beyond Gatsby's dream.

The sentence's surplus or even exorbitance can carry across the sentence boundary, producing a variant on the appositional structure -- the sentence fragment. In the novel, Nick reflects on Gatsby's statement of Daisy's voice:

It was full of money -- that was the inexhaustible charm that rose and fell in it, the jingle of it, the cymbals' song of it.... High in a white palace the king's daughter, the golden girl ....(p. 115)

The double appositional construction, "the jingle of it, the cymbals' song of it", is in apposition to "the inexhaustible charm that rose and fell in it". This construction seems inexhaustible itself, endlessly responding to itself: ellipses here seem to signify the sentence's resistance to closure, suggesting that the sentence has no conclusion just like dream, once this syntactic resource and these wordings of romance are in play. Then the abundance of this appositional surplus spills over the receding sentence boundary in a syntactic fragment, and finally sets sight on the transformative goal: "High in a white palace the king's daughter, the golden girl". All these appositional structures seem like an imitation of Gatsby's process of dream striving and attaining.

\section{Use of Prepositional Phrases}


Another excellent use of syntactical features lies in Fitzgerald's employment of prepositional phrases. Prepositional phrases usually function as adverbials and hence are grammatically extraneous -- in other words, they could be moved around the sentence or deleted altogether. But the fact that they are grammatically extraneous does not mean that they are semantically extraneous. On the contrary, the writer masterly uses prepositional phrases to convey much of the scene-setting and atmosphere of a text. Consider the following passage in the novel:

Already it was deep summer on roadhouse roofs and in front of wayside garages, where new red petrol-pumps sat out in pools of light and when I reached my estate at West Egg I ran the car under its shed and sat for a while on an abandoned grass roller in the yard. The wind had blown off, leaving a loud, bright night, with wings beating in the trees and a persistent organ sound as the full bellows of the earth blew the frogs full of life. The silhouette of a moving cat wavered across the moonlight, and, turning my head to watch it, I saw that I was not alone -- fifty feet away a figure had emerged from the shadow of my neighbor's mansion and was standing with his hand in his pockets regarding the silver pepper of the stars. Something in his leisurely movements and the secure position of his feet upon the lawn suggested that it was Mr. Gatsby himself, come out to determine what share was his of our local heavens. (p.25)

This passage consists of four sentences, each containing several prepositional phrases. As Lara Wright and Jonathan Hope (2000: 152) point out, prepositions have an orientating function, that is, they can function to anchor a text in time and space. This implies an awareness who is doing the orienting, and who is being oriented. Take the first sentence in the above extract for example. Without the prepositional phrases such as "a roadhouse roofs, in front of wayside garages, out in pools of light, at West Egg, under its shed, for a while, on an abandoned grass roller, and in the yard", the sentence still functions grammatically, and the action is conveyed, but we as readers do not know whereabouts the action happens, and therefore cannot infer why it happens. Thus the effect is weakened. Meanwhile, the plurality of the noun like "roofs, garages, petrol-pumps" gives clues from which we can infer that it was deep summer in all these places. However, the adjectives "house, wayside" serve to restrict the nouns, indicating that it is summer not on all roofs and in front of all garages, only "roadhouse roofs, and wayside garages with new red petrol-pumps outside". Therefore, what sounds like a broad statement about the season turns out to be a highly specific description of a particular location. This precision of location gives this sentence a slightly disturbing tension because later on in the novel, Myrtle Wilson is killed in an accident that has occurred just at such a wayside garage, that is, the author already predicts events to come in this description.

In this extract, all four sentences with prepositional phrases have the cumulative effect of withholding the new information till the last sentence: the introduction of Gatsby, thus creating suspense.

From this example, we can clearly see that prepositional phrases can produce the effect of locating a passage in time or space, thus providing a good way to describe the surroundings and evoke moods; it can also act as a delaying tactic, serving to generate suspense as well as to create interest and expectation.

\section{REFERENCES}

[1] Associated Content. (2004). T. S. Eliot's genre, writing style, issues and their relevance today. http://www. associatedcontent. com/article/119569/ts_eliots_genre_writing_style

[2] Baughman, Judith S. and Broccoli, Matthew J. (2000). Literary Masters Series (Vol.1 Fitzgerald). Farmington Hills, Michigan: The Gale Group.

[3] Berman, Ronald. (2001). Fitzgerald, Hemingway, and The Twenties. London: the University of Alabama press.

[4] Bewley, Marius. (1963). Scott Fitzgerald's criticism of America. In. Mizener, Arthur. (Ed.) F. Scott Fitzgerald: A Collection of Critical Essays (p. 125). Englewood Cliffs: Prentice-Hall.

[5] Booth, Wayne C. (1961). The Rhetoric of Fiction. Harmondsworth: Penguin Books Ltd.

[6] Bruccoli, Matthew J. (1971). ed. Profile of F. Scott Fitzgerald. Columbus, Ohio: Merrill.

[7] Bruccoli, Matthew J. (1985). ed. New Essays on The Great Gatsby. Cambridge: Cambridge University Press.

[8] Bullock, Alan, Oliver S. Brass and Stephen Trombley. ed. (1988). The Fontana Dictionary of Modern Thought. Fontana Press.

[9] Callahan, John. F. (1972). The Illusion of a Nation: Myth and History in the Novel of F. Scott Fitzgerald. Illinois: University of Illinois Press.

[10] Carter, Ronald and Paul Simpson. (1995). Language, Discourse, and Literature: An Introductory Reader in Discourse Stylistics. London: New York Taylor\& Francis Routledge.

[11] Cooperman, Stanley. (1996). Scott Fitzgerald's The Great Gatsby.

[12] Chen xihua. (2006). On Description of Daisy's Voice in The Great Gatsby. In Qujing Normal School Newspaper.

[13] Donaldson, Scott. ed. (1984). Critical Essays on F. S. Fitzgerald's The Great Gatsby. Boston: G.K.Hall.

[14] Eble, Kenneth. ed. (1973). F. Scott Fitzgerald: A Collection of Criticism. New York: McGraw-Hill.

[15] Fitzgerald, Francis Scott. (2003). The Great Gatsby. Qingdao: Qingdao Press

[16] Hook, Andrew. (2002). F. Scott Fitzgerald: a literary life. Basingstoke: Palgrave Macmillan.

[17] Jakobson, Roman. (1976). Linguistics and poetics. In. Chatman S. \& Levin S. (Ed.) Essays on the Language of Literature (pp.299-303)

[18] Leech, G. N. and M. H. Short. (2000). Style in Fiction: A Linguistic Introduction to English Fictional Prose. Beijing: Foreign Language Teaching and Research Press.

[19] Long, Robert Emmet. (1979). The Achieving of The Great Gatsby. Lewisburg Pa.: Bucknell University Press.

[20] Miller, James E., Jr. (1964). F. Scott Fitzgerald: His Art and His Technique. New York: New York University Press.

[21] Ma Ruixiang. (2004). On Color Description of Scott Fitzgerald's Writings. In Shenyang University Newspaper

[22] Neufeldt, Victoria and David b. Guralnik. ed. (1997). Webster's New World College Dictionary. Macmillan. 
[23] Thornborrow, Joanna. (2000). Patters in Language: Stylistics for Students of Language and Literature. Beijing: Foreign language Teaching and Researching press.

[24] Tory, William. (1945). Scott Fitzgerald-the authority of failure. In Arthur Mizener (Ed.). F.Scott Fitzgerald - A Collection of Critical Essays. Englewood Cliffs, NJ: Prentice-Hall.

[25] Piper, Henry Dan. ed. (1970). Fitzgerald's The Great Gatsby: The Novel, the Critics, the Background. New York: Scribners.

[26] Posnock, Ross. (1984). Fitzgerald's critique of capitalism in The Great Gatsby. In. Donaldson, Scott. (Ed.) Critical Essays on F. S. Fitzgerald's The Great Gatsby. Boston: G.K.Hall.

[27] Pelzer, Linda Claycomb. (2000). Student Companion to F. Scott Fitzgerald. Westport, Conn: Greenwood Press.

[28] Prigozy, Ruth. ed. (2001). The Cambridge Companion to F. Scott Fitzgerald. Cambridge: Cambridge University Press.

[29] Wright, Laura \& Hope, Jonathan. (2000). Stylistics: A Practical Coursebook. Beijing: Foreign Languages Teaching and Research Press.

Xiangqi Liu was born in Qingdao, China in 1978. She received her master degree in linguistics from Ocean University of China, Qingdao, China in 2009.

She is currently a lecturer in the School of Foreign Languages, Qingdao University of Science and Technology, Qingdao, China. Her research interests include stylistics and Chinese American literature. 